WHOI -75-66

TOW SPECTRA FROM MODE

by

Eli Joel Katz

\author{
WOODS HOLE OCEANOGRAPHIC INSTITUTION \\ Woods Hole, Massachusetts 02543
}

December 1975

Prepared for the Office of Naval Research under Contract N00014-70-C-0205; NR 263-103 and NSE/IDOE Grant GX-34906.

Reproduction in whole or in part is permitted for cony purpose of the United States Govermment. In citing this report in a bibliography, the reference given should be to the "Joumal of Geophysical Research, Vol. 80, No. 9, March 20, $1975^{\prime \prime}$.

Approved for public release; distribution uniimited. 


\title{
Tow Spectra From MODE
}

\author{
ELI Joel, Katz \\ Woods Hale Occanographic Instilution, Woods Hole, Massachuselts 02543
}

\begin{abstract}
Towed sensor data from the main thermocline in the Sargasso Sta south of Bermuda during the Mid-Ocean Dynamics Experiment are reported and compared with the Garrett and Munk internal wave Mid-Ocan ? model. The tows consisted or two sensor suites vertically spaced from 0.015 to 5 cycles $\mathrm{km}^{-1}$ results in a vertical displacement spectsum of the isopycnul surface that is from 0.015 to 5 cycles $\mathrm{km}^{-1}$ results in a vertical displaces in the same area. In this wave number band, agreement with both the 1972 and the 1975 versions of the Garretl and Munk internal wave model is good. ment with both the tained from the temperature fluctuations at the two separations describe the horizontal wave number bands over which vertical coherency is lost. The 1975 model underestimates coherency but can be brought into better agreement by reducing the 'mode number scale.'
\end{abstract}

In a previous paper $[K a \mid z, 1973]$ the results of a series of low's were presented. The observations closely approximated a direct measure of the wave number spectra of the vertical displacement of an isopyenal surface. The tows were made at a variuble depth following an isothermal/isopycnal surface, and thus the need for deriving displacement spectra indirectly from temptrature variance spectra was eliminated. The region chosen for the observations was in the main thermocline of the Sargasso Sea south of Bermuda at depths greater than $600 \mathrm{~m}$ below the surface. This is a region where temperature and salinity are highly correlated (salinity was nonetheless observed) and where the main thermocline is separated from the sersonal thermocline by an intermediate minimum in the Vaisäla frequency profile associated with the "18" water" [Worthington, 1959]. From three separate cruises to the area and a variety of tracks (a 550-km reach, an equilateral triangle, ctc.), six independent estimates of the displacement spectrum were shown to overlap and combine into a single spectrum. Covering the wave band from 0.02 to 30 cycles $\mathrm{km}^{-1}$, this specirum is monotonically decreasing with wave number, independent of direction, and stalionary.

The-displacement-spectrum was compared with the appropriate projection of the Garrent and Munk [1972] internal wave inodel (familiarly called GM72) and with a set of four tou spectra that they had selected to help build up their model. Agreement between the above Sargasso Sea spectrum and the earlicr data (as interpreted by Garretl and Munk) was encouraging. Two were overlapped by the Sargasso Sea spectrum: the LaFonds' spectrum derived from neas-surface thermistor chain tows off San Diego and Ewart's spectrum derived from temperature data at constant depth in the shallow main thermocline of the state of Washington. The other two observations had parallel spectral slopes but were higher in amplitude. These comparisons are made after weighting encrgy density by the local Väisälä frequency as suggested by WKB wave solutions [Fofonoff. 1969].

Agreement with the GM72 model was good only for wave numbers smaller than scveral cycles per kilometer. A high wate number cutoft predicted by the model, as a function of $V$ aisitla frequency, was absent from all of the relevant observations. Al best, the Sargasso Sea spectrum, which was the first (1) bridge the gap between low and high wave numbers. sughested a break in spectral slope: from a power law of - 1.55

Copyright (c) 1975 by the American Geophysical Union. at wave numbers smaller than $I$ cycle $\mathrm{km}^{-1}$ to -2.3 at the high wave number end. In an attempt to incorporate this and other discrepancies between new observations and GM72 the modelers adjusted the functional way that they had distributed the energy at a particular frequency across the horizontal wave number axis [Garrerf and $M$ unk, 1975]. The high wave number cutoff was replaced by a -2.5 power law, and good agreement between data and the revised model, GM75, was demonstrated [Garrell and Munk. 1975, Figure 3].

A perplexing question facing the interpretation of tow spectra of either vertical displacement or temperature is that of deciding which wavelength band is dominated by which physical process, when one assumes that such dichotomies exist. This has led to attempts to compare recently observed spectral slopes with single process model predictions [ $M c K e a n$ and Ewart, 1974; Keunecke and Magaard, 1974]. In the internal wave model of Garretl and Munk, this slope is a parameter of the model, which is only partially constrained by fitting frequency spectra from moored sensors and floats. They have so far been able to adjust the model to obtain better spectral fits. It is when observations from two or more different projections in wave number-frequency space cannot be rationalized by a single internal wave model that the model may help with the identification of the internal wave bandwidth.

Garrett and Munk have discussed two other tow spectra to assist in the testing of internal wave models: the coherence between verticalty separated towed sensors and the coherence between two tows along the same path (time-tagged coherence). These spectra include the effect of vertical wave number and frequency on horizontal wave number spectra obtained from tows, thereby contributing to a broader understanding of the energy spectrum of ocean variability.

\section{Observations and Data ANalysis}

During $A$ pril and June 1973 a depth-controlled tow fish was "flown" for a total of 13 days within $100 \mathrm{~km}$ of the center of the Mid-Ocean Dynamics Experiment $\left(29^{\circ} \mathrm{N}, 68^{\circ} 40^{\prime} \mathrm{W}\right.$, deep water southwest of Bermuda). A weighted sensor package was suspended from the control fish and towed either 11 or $21 \mathrm{~m}$ below it. The sensor package contained demperature, pressure, and conductivity sensors (from the Plessey ventical profiler, model 9007). Mounted on the low fish above were second matching pressure and temperature sensors. Data were continuously Iransmitted to a shipboard computer and recorded 
every half second. Towing speed varied between 2.1 and 3.0 $\mathrm{m} \mathrm{s}^{-1}$ on various legs. Depth of tow varied between 700 and $800 \mathrm{~m}$ as the $12^{\circ} \mathrm{C}$ isotherm was bracketed by the two sets of sensors. The design of the tow fish and the success of its depth control system have been reported by Hess and Nowak [1974].

From the above data set a subset was extracted lor spectral analysis. Only periods of towing where the isotherm was firmly bracketed for long straight reaches were analyzed. These data were then averaged by using hourly averages of speed from the good Loran $C$ coverage in the area, to obtain an interpolated isotherm depth along every estimated $100 \mathrm{~m}$ of track.

The resolution of the temperature sensor is about 2 mdeg. With the mean vertical temperature gradient being 22.5 mdeg $\mathrm{m}^{-1}$ the resolution leads to a relatively small error in computing the isotherm depth. The error due to the resolution of the pressure sensor is comparatively small. However, the interpolation between the two sensors necessarily assumes a linear Bradient. At 10-m separation, error in this interpolation can be estimated by considering the accumulated variance of temperature for verlical wavelengths of 0.05 cycle $\mathrm{m}^{-1}$ to infinity. This variance can be calculated from the MODE density program of STD lowerings reported by Hayes ef al. [1975]. In the main thermocline, one obtains an $\mathrm{rms}$ value of $20 \mathrm{mdeg}$. High vertical wave numbers can therefore be thought to introduce an error of about I m when one interpolates between the two sensors.

A nother possible source of error is the use of the isotherm displacement to represent the isopycnal displacement. The ratio of the change of sigma $t$ with temperature to that of sigma $t$ with salinity is $1 \%\left(4^{\circ} \mathrm{C}\right)^{-1}$ in this region. For the isothermal surface to diverge more than a meter from the isopyenal surface therelore requires the salinity to change more than $0.005 \%$ at a given temperature. It is not known if intermittent or systematic changes of that magnitude occur in the temperature-salinity correlation over distances of $100 \mathrm{~km}$. In fact, the sensor used is unable to reliably sense rapid fuctuations of salinity less than $0.015 \%$, and an observed drift of $0.01 \%_{0}(100 \mathrm{~km})^{-1}$ in the sensor masks smaller continuous changes.

Varialions in towing speed over less than an hour will tend to blur the spectra at high wave numbers. Sample calculations suggest that this is nol particularly worrisome.

The isothermal surfaces have very definite large-scale trends. The full set of data from the tows, which consists of multiple crossings at $120^{\circ}$ to one another, has been conloured and will be avjiflable in the MODE Synoptic Allas scheduled for publication early in 1975. The mean slope of the isothermal displacement over $100-\mathrm{km}$ track lengths approached values of $1 \mathrm{~m}$ $\mathrm{km}^{-1}$ ut times. This trend and lower wave number variation were removed from the analysis by rewriting the data series as first differences and then recoloring the spectra.

\section{MODE Displacement SPectrum}

The displacement spectre of eight selected $65-\mathrm{km}$ segments were averaged to obtain the single MODE spectrum shown in Figures I and 2 (tows 703/704). The towed sensors were verlically separated by $11 \mathrm{~m}$. The data are from two periods sepurated by 2 weeks in time and at three different headings. The spectral estimates have been averaged without regard to time or direction as suggested by the earlier results.

The present spectrum and two representative previous specIra are compared in Figure 1. It again confirms that there is a feproutucible average displacement spectrum for this area. The approximation and deviation from an $\alpha^{-1}$ power law is indicated on the figure. No single power law describes the nearly 3 th decades of wave numbers. It is equally correct to speak about a central wave number band with a -2 slope as it is to divide the spectrum into two segments with slopes less than and grealer than -2 . Where previously a value of -1.55 was suggested for the wave number band $10^{-1}$ to 1 cycle $\mathrm{km}^{-1}$, the equivalent calculation for tow $703 / 704$ yields -1.75 . Owing to the improvement of the measuring technique and because tows 300 and 400 used $1 \mathrm{~km}$ rather than $100 \mathrm{~m}$ spaced data, more confidence is placed in the present estimate.

Also shown in Figure 1 is the MODE spectrum in a variance preserving plot. When a planimeter is applied to the area under the curve, the rms vertical displacement of the surface about its mean slope in the wave number band from $10^{-2}$ to $10^{1}$ cycles $\mathrm{km}^{-1}$ is $7.5 \mathrm{~m}$, giving a measure of the size of the phenomenon being observed. Broken down into decades of wave numbers one obtains the rollowing description;

$\begin{array}{cc}\text { Wave Number Band } & \text { rms Displacement } \\ 10^{-1}-10^{-1} \text { cycle } \mathrm{km}^{-1} & 6.7 \mathrm{~m} \\ 10^{-1}-1 \text { cycle } \mathrm{km}^{-1} & 3.1 \mathrm{~m} \\ 1-10 \text { cycles } \mathrm{km}^{-1} & 1.2 \mathrm{~m}\end{array}$

The displacement in the highest wave number band is of comparable amplitude to our anticipated resolution, and if the uncertainty was all at the higher end of the spectrum, this displacement would be unresolvable. The spectrum does not indicate that this is the case, since it shows no indication of becoming white until it reaches the highest wave numbers, but one should be cautious discussing the slope of the displacement spectrum at $\alpha>10^{-1}$ cycle $\mathrm{km}^{-1}$. Even more caution is advised when converting temperature spectra to displacement spectra at high wave numbers.

The weighted MODE spectrum is compared with the Garrett and Munk model in Figure 2. In the band compared, only a slight edge can be given to the revised model, because the high wave number cutoff of GM72 only begins to dominate the spectrum at the highest wave number estimates. The greater part of the variance of the vertical displacement is independent of the redistribution of energy that resulted in GM75. There is a suggestion that the models are high in amplitude over the entire band. Both models assume an energy density of 0.382 joule $\mathrm{cm}^{-2}$ to fit a diverse collection of mooring and tow data. A better fit between the MODE spectrum and GM75 is obtained if the constant is reduced by a third; i.e., $E$ (dimensionless) = $4 \pi / 3 \times 10^{-8}$. Alternatively, the same effect can be achieved by a one-third reduction in the equivalent number of modes at the inertial frequency [Garrett and Munk, 1972, equation 6.22].

\section{Vertical Coherence Spectra}

The two temperature sensors bracketing the tracked isotherm provide the data to compute estimates of the verlical coherence spectra. It is only an approximation because the vertical gradient must be assumed to be constant in order to interpret the coherence between temperature signals as the coherence between vertical displacements.

The coherence spectra between the two signals are obtained from their cross spectra and the coherences squared are plotled in Figure 3 as a function of horizontal wave number. The corresponding phase spectra between the quadrature and cospectra estimates are indistinguishable from zero. The data from 11-m separations are from the same eight segments used to obtain the displacement spectrum. For $21 \mathrm{~m}$ a single track 


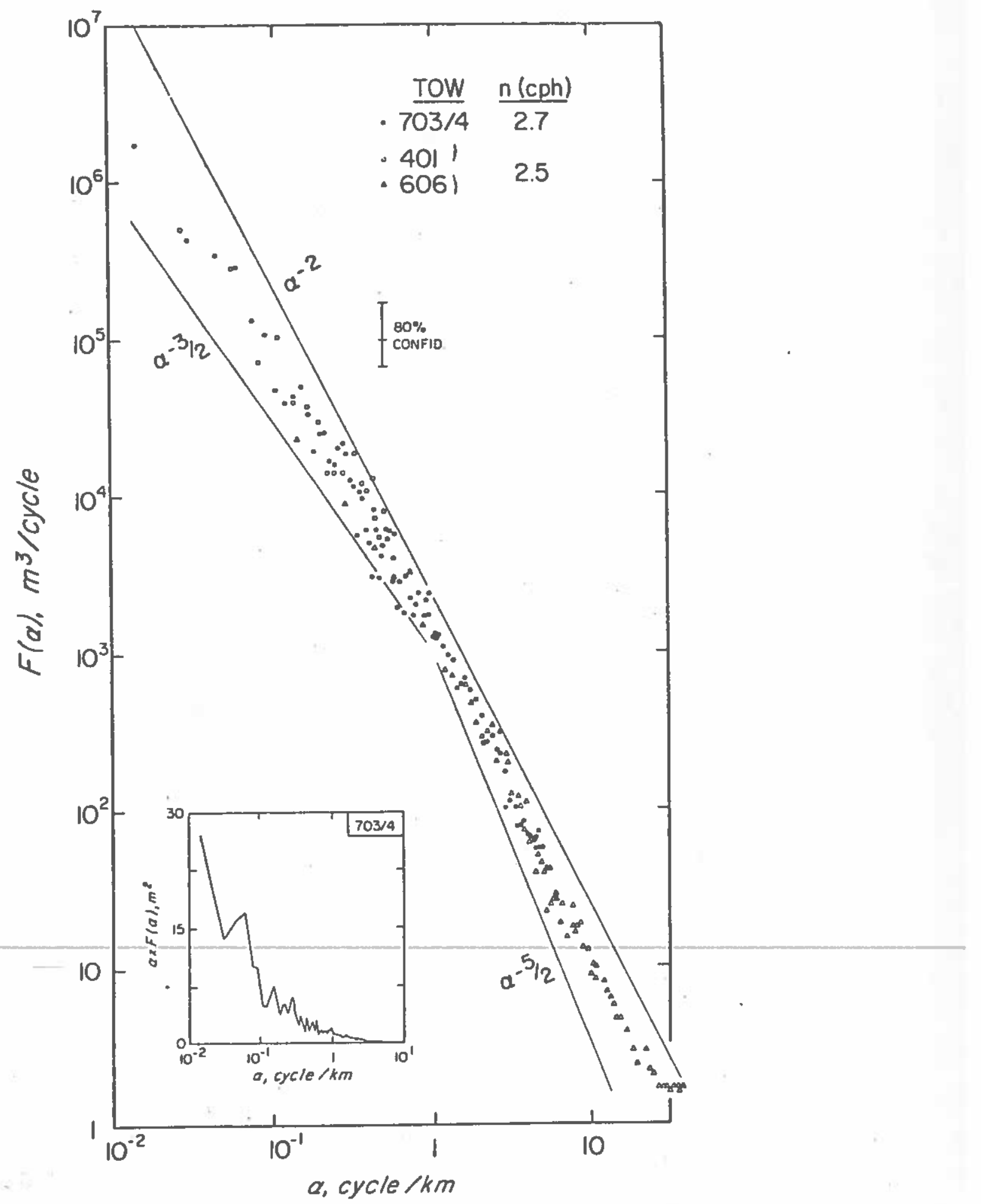

Fig. 1. MODE vertical displacement spectrum of the $12^{\circ}$ isotherm. The average specteum from ejght $65-\mathrm{km}$ tracks (tows $703 / 704$ ) compared with earlier tows (401 and 606) in the same area. The energy density of the latter has been incrensed by the ratio of their Văisala frequencies, 2.7/2.5. A variance preserving presentution of the MODE spectrum is given in the insert.

of $128-\mathrm{km}$ length observed two months earlier was segmented into five series and analyzed by $50 \%$ overlapping of the pieces und then using a Hanning window. The same analysis on a long track from tow 703 (11-m separation) repeats the result shuwn for the eight separate segments.

The difference between the coherence spectra at the two scparations is statistically significant. The loss of coherency oc- curs at wave numbers that are generally thought to be dominated by internal waves. The towed vertical coherence predicted by GM75 is roughly parallel to each curve in Figure 3 but displaced to lower wave numbers. This displacement is indicated in Figure 4, where values of coherence $(R)$ equal to $0.9,0.7$, and 0.5 are compared with the prediclions. The 0.7 prediction, for example, predicts a wave number hall of that 


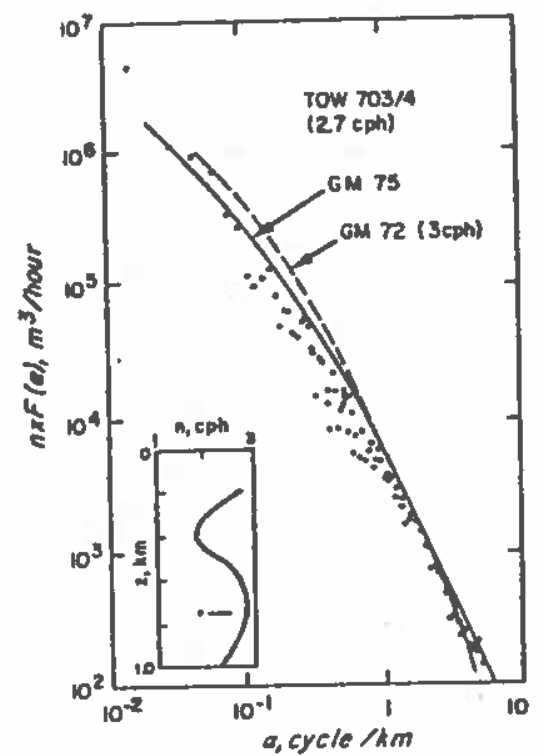

Fig. 2. MODE spectrum compared with the Garrell and Munk internal wave models. The local Vaisala frequency profile and the average depth of tow is given in the insett. The 1972 model is for a vaisali lrequency of $3 \mathrm{cph}$.

observed. It appears that the higher vertical wave numbers have been given relatively too energetic a role in GM75.

To force GM75 to fit the observations requires a mode number scale $\left(j_{*}\right)$ near unity in contrast to the value of 6 that they adopted. The physical significance of this scaling factor (which is not straightforward) and several values estimated from vertical and horizontal coherences observed in frequency space ure discussed by Garrelt and Munk [1975]. The tow spectra yield the lowest value so far but further discussion is best deferred until several recent field programs are reported.

Also included in Figure 4 are the results of McKean and Ewarr [1974] as roughly estimated from their coherence curves (their Figures $8 b$ and $8 c$ ). The vertical separations are $2 / 3$ and I $\mathrm{m}$ and the Vaisala frequency is assumed to be 1.5 cycles $\mathrm{h}^{-1}$ (the frequency was not given, but the tows were at $1-\mathrm{km}$ depth, $10 \mathrm{~km}$ from a stecp seamount in the eastern Pacific). McKean [1974] attributes the drop-off in coherence at his small

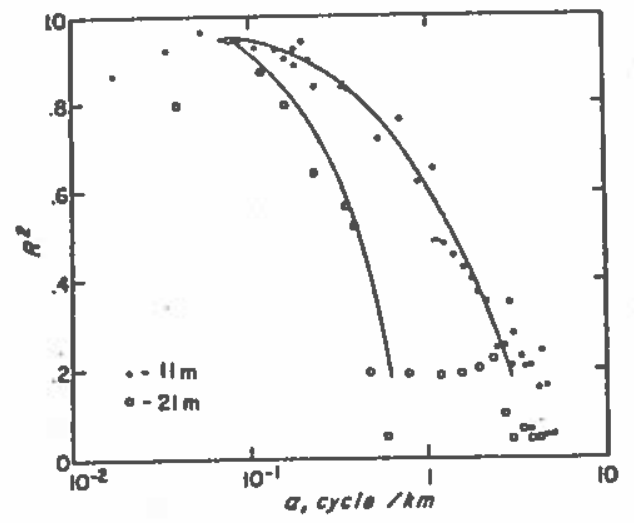

Fig. 3. Towed vertical coherence spectra for 11. and 21-m separmions. The former is derived from an average of the eight segments used to estimate the MODE displacement spectrum. At higher wuve numbers, estimates are averaged over ten adjacent bands as $u$ cll. The $21 \cdot \mathrm{m}$ separation is Irom \& single $128-\mathrm{km}$ track (tow 702), segmented into five pieces and overlapped. At higher wave numbers, estinuates are averaged over first three, then ten, adjacent bands. Note that the urdinate is the coherence squared. The bias and confidence bands ure relatively small throughout.

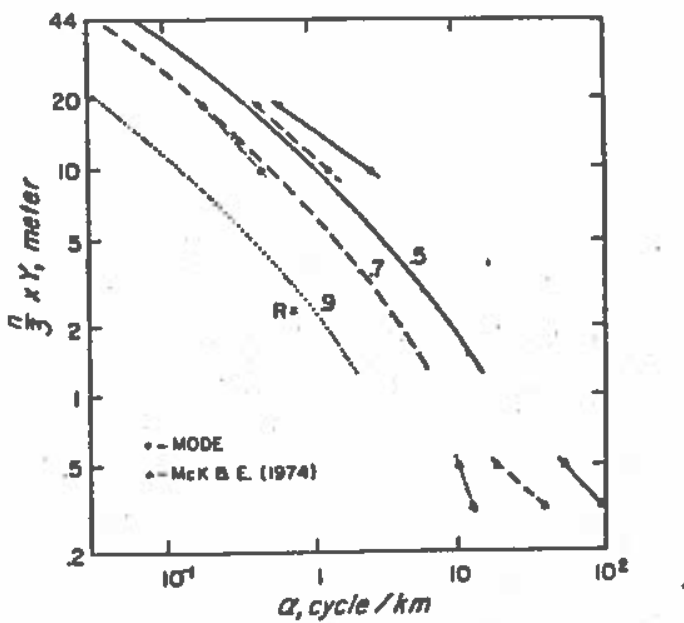

Fig. 4. Towed vertical coherence estimates compared with GM75. The curves are from the model. The data points are from Figure 3 with $Y$ (vertical separation) $=11$ and $21 \mathrm{~m}$ and $n=2.7 \mathrm{cph}$ and after McKean and $E$ want [1974] with $Y=3$ and $1 \mathrm{~m}$ and $n$ estimated at 1.5 eph. Values of $a$ for $R$ (eoherence) $=0.9,0.7$, and 0.5 are plotted for each data set.

separations to fine structure contamination, which is outside the scope of GM75. On the other hand, perhaps artifically or perhaps causally, the revised model has been able to do a creditable job of modeling temperature spectra converted to displacement spectra down to horizontal wave numbers in the $10^{*}-10^{*}$ cycle $\mathrm{km}^{-*}$ band [Zenk and Katz, 1975]. When one interpolates from Figure 1, the displacement amplitude of this high wave number band is less than $10 \mathrm{~cm}$. Thus the separation is not small in relation to wave amplitude, and the inclusion of their data on Figure 4 cannot be dismissed on a relative amplitude argument. The observations are too widely separated on the figure to connect them, but their relationship to GM75 is consistent. Further observational data, at larger separations as well as intermediate values, are needed.

\section{Concluding Remarks}

Though the observations have been repeatedly applied to a comparison with the Garrett and Munk model, they are obviously useful touchstones for any other internal wave models or theories that wish to explain the vertical displacement field in wave number space. Unlike frequency spectra, where the internal wave frequency band is theoretically bounded by the incrtial and Väisăla frequencies, no such natural bounds or signposts can be defined for wave number spectra. Interpretation of wave number spectra is therefore less precise.

With a growing though still small collection of tow spectra having been reported in the literature it appears that they themselves do not as yet clearly differentiate between the various physical processes that one expects they teflect. The more modest objective of a quantitative description of spatial variability is, however, being met.

Acknowledgments. The gathering of these data and their analysis were supported by the National Science Foundation, Ofice of the International Decade of Ocean Exploration, under grant GX-34906. The design and construction of the depth controllable tow fish were supported by the Ofice of Naval Research under contract N0014-70C-0205. Richard Nowak supervised the design of the tow fish and its operation at sea on the R.V. Chain, cruise 112. Among the many other contributors to the field experiment. Frederick Hess and John Racklifie deserve special mention. Discussions with Melbourne Briscoe during the data analysis period are also gratefully recorded. This paper is contribution 3455 from the Woods Hole Oceanographic Institution and MODE contribution 13. 


\section{References}

Folınof. N. P., Role of the NDBS in future natural varjability studies of the North Atlantic. Proceedings of the First Scientific Advisory Meeting. National Data Buoy Development Project, pp. S0-61, U.S. Coast Guard Acad., New London, Conn., 1969.

Garrett, C., and W. Munk. Space-time scales of internal waves, Gruphys. Fluid Dyn. 2. 225-264, 1972.

Gurrett. C., and W. Munk, Space-time scales of internal waves: A progress report, J. Geophys. Res., 80, 291-297. 1975.

Haycs, S. P., T. M. Joyce, and R. C. Millard, Jr., Measurements of verticul fine-structure in the Sargasso Sea, J. Geophys. Res., 80, 314-319, 1975.

Hexs, F., and R. Nowak, Medjum depth controllable towed instrument plutform, Proc. IEEE Int. Conf. Eng. Ocean Environ., pp. 187-191. 1974.

Kalz, E. J., Profile of an isopyenal surlace in the main thermocline of the Sargasso Sen, J. Phys. Oceanogr., 3(4), 448-457, 1973.
Keunecke, H. H., and L. Magalard, Measurements by means of towed thermistor cables and problems of their interpretation with respect 10 mesoscale processes. puper presented at the Sixth Colfoquium on the Hydrodynamics of the Ocean, Univ. of Liège, Liċge, Belgium, 1974.

McKean, R. S. Interpretation of internal wave measurements in the presence of fine-struclure, J. Phys. Oceanogr., \& (2), 200-213, 1974.

McKean, R, S.t and T. E, Ewar. Temperatuse specira in the deep ocean of Hawaii, J. Phys. Oceanogr., 4(2), 191-199, 1974.

Worthington, L. V., The $18^{\circ}$ water in the Sargasso Sea, Deep Seo Res. 5. 297-305, 1959 .

Zenk, W., and E. J. Katz, On the stationarity of temperature at high horizontal wave numbers, submitted $10 \mathrm{~J}$. Geophys. Res., 1975.

(Received October 18, 1974;

accepled November 19, 1974.) 
FOR UNCLASSIFIED TECHNICAL REPORTS, REPRINTS, \& FINAL REPORTS PUBLISHED BY OCEANOGRAPHIC CONTRACTORS

OF THE OCEAN SCIENCE AND TECHNOLOGY DIVISION

OF THE OFFICE OF NAVAL RESEARCH

(REVISED OCT . 1975)

Director of Defense Research and Engineering Office of the Secretary of Defense Washington, DC 20301

ATTN: Office Assistant Director (Research)

Office of Naval Research

Arlington, VA 22217

3 ATTN: (Code 480)

1 ATTN: (Code 460)

1 ATTN: (Code 102-OS)

6 ATTN: (Code 102IP)

1 ATTN: (Code 200)

1 LCDR David Cacchione, (USN)

ONR Representative

Woods Hole Oceanographic Inst.

Woods Hole, MA 02543

1 Office of Naval Research

Branch office

495 Summer Street

Boston, MA 02210
12 Defense Documentation Center

Cameron Station

Alexandria, VA 22314

Commander

Naval Oceanographic Office

Washington, DC 20390

1 ATTN: Code 1640

I ATTN: Code 70

Director

Naval Research Laboratory

Washington, DC 20375

6 ATTN: Library, Code 2620

1 Nationa1 Oceanographic Data Center

National Oceanic $\&$ Atmospheric Administration

Rockville, MD 20852 

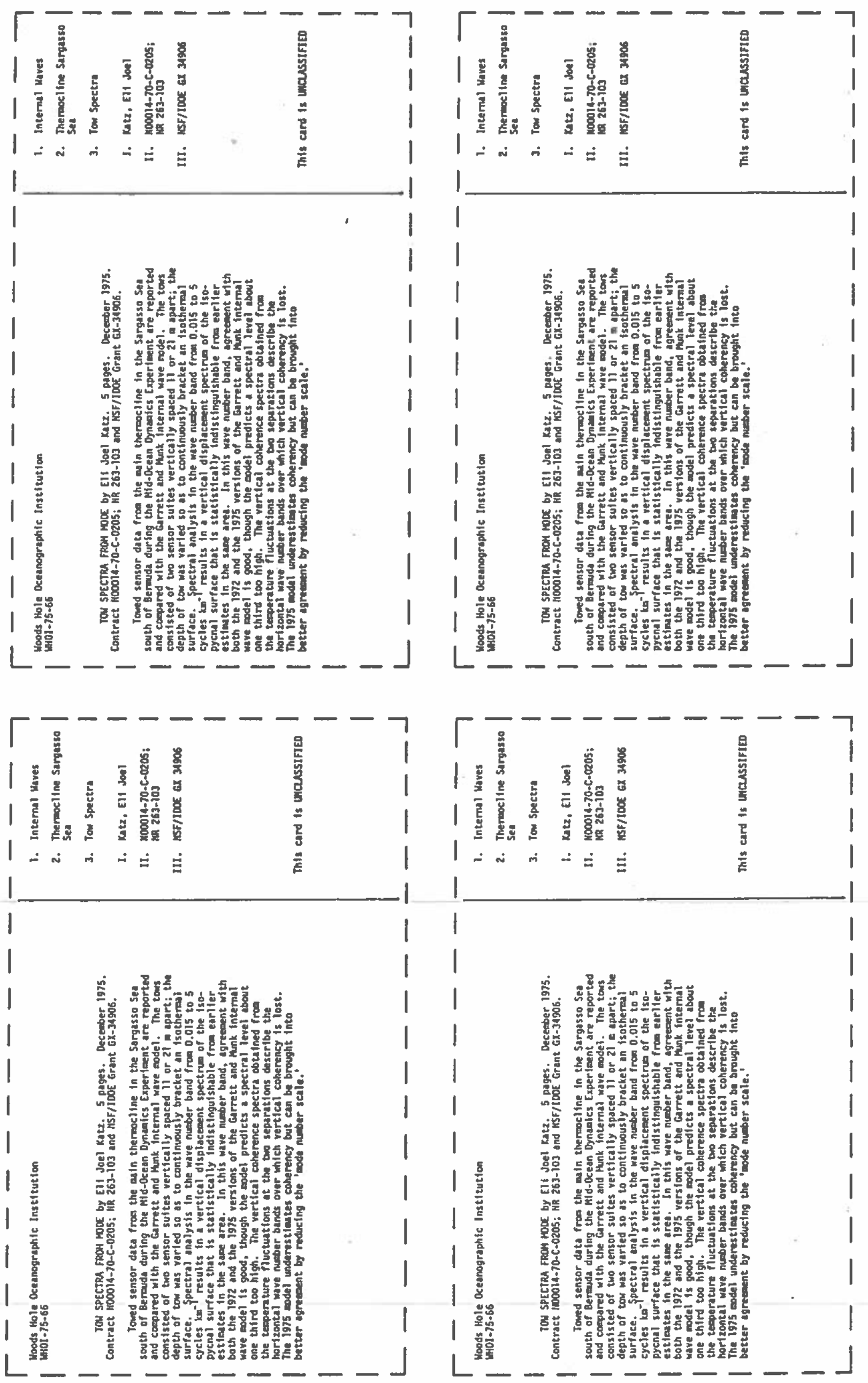
UNCLASSIFIED

$12 / 30 / 75$

SECURITY CLASSIFICATION OF THIS PAGE (When Dote Entered)

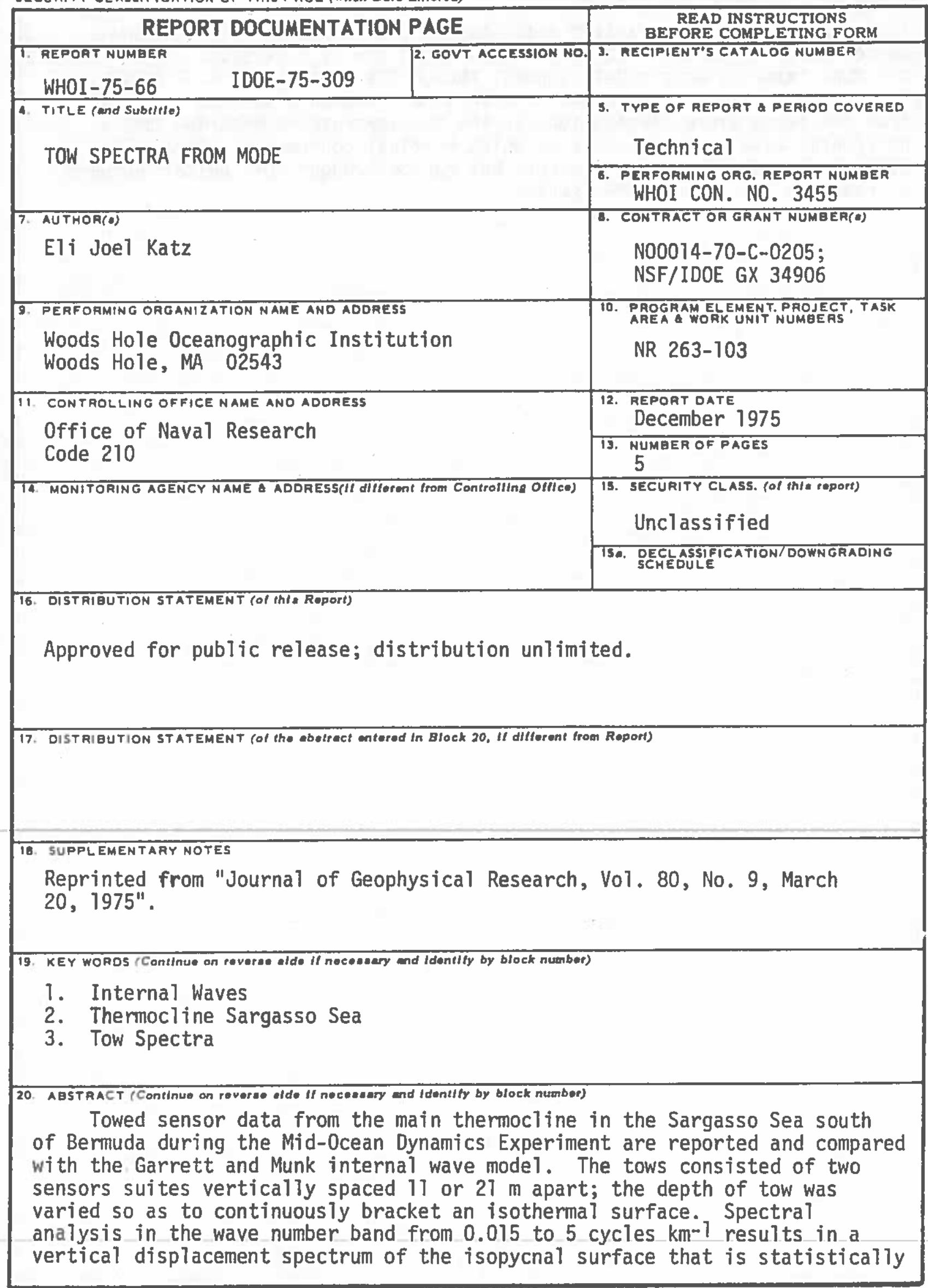


SECUAITY CLASSIFICATION OF THIS PAGE (Thon DEIA Fintarad)

indistinguishable from earlier estimates in the same area. In this wave number band, agreement with both the 1972 and the 1975 versions of the Garrett and Munk internal wave model is good, though the model predicts a spectra level about one third too high. The vertical coherence spectra obtained from the temperature fluctuations at the two separations describe the horizontal wave number bands over which vertical coherency is lost. The 1975 model underestimates coherency but can be brought into better agreement by reducing the 'mode number scale.' 